\title{
The Application of Ultrasonic Levitation in the Rotor Support
}

WANG Hong-chen ${ }^{1,2}$, YANG Zhi-gang ${ }^{1}$, LIU Lei ${ }^{1}$

${ }^{1}$ College of Mechanical Science and Engineering, Jilin University, Changchun 130025, China. E-mail: whcwanghongchen@126.com

${ }^{2}$ Engineering Training Cenfer, Changchun Institute of Technology, Changchun 130012, China. E-mail: 383629034@qq.com, E-mail: 490855545@qq.com

In order to enhance the stiffness of the gas film and increase the maximum speed of the rotor, this paper proposes an ultrasonic levitation structure with a cone type bidirectional supporting motor. The performance of the conicaltype ultrasonic levitation support is analysed and tested according the relationship between the levitation force and levitation gap. Through theoretical analysis it is realised that the critical speed and vibration mode of the motor rotor is affected by the change of levitation gap in the ultrasonic levitation condition. The experiments with levitation gap and the maximum speed of the motor rotor show the structure can reduce the suspended gap, while simultaneously the maximum speed of the rotor is increased.

Keywords: Ultrasonic Vibration, Suspension Support, Squeeze Film, Suspension Clearance

\section{Acknowledgement}

Acknowledgement is arrange behind results and before References without numbering. References are strictly only by this format, font and automatically numbering.

\section{References}

[1] MATSUO, E., KOIKE. Y., NAKAMURA. K., UEHA, S. etc.(2000). Holding characteristics of planar objects suspended by near-field acoustic levitation. In: Ultrasonics, pp. $60-63$.

[2] CHANG Ying, YANG Zhi-gang, WU Bo-da etc. (2004). Experimental study on bearing capacity and suspension performance of Ultrasonic Bearing. In: Piezoelectrics \& Acoustooptics, Vol. 2, pp. 197 - 199.

[3] CHANGYing, WUBo-da, YANGZhi-gangetc. (2004). The antifriction performance ability and the ultrasonic suspension thrust bearing. In: Journal of Jilin University, Vol.34: pp. 221 - 225.

[4] ZENG Ping, CAO Yong-chang, CHENG Guang-ming etc. (2006). The mechanism analysis of friction reduction of UltrasonicBearing. In: Lubricationandseal, Vol.182: pp. 18 - 21.

[5] CHANGYing, WUBo-da, CHENG Guang-ming etc. (2006). Piezoelectric modal analysis and experimental study of Ultrasonic Bearing. In: Journal of Harbin Institute of Technology, Vol.68: pp. 752 - 759.

[6] WU Bo-da, CHANG Ying, YANG Zhi-gang etc. (2004). Theoretical analysis and experimental study of ultrasonic vibration anti-frictionperformance. In: China Mechanical Engineering, Vol.15: pp. 813 - 815.

[7] PENG Tai-jiang, YANG Zhi-gang, TIAN Feng-jun etc. (2008). Technology of ultrasonic levitation supporting shaft. In: Optics and precision engineering, Vol.16: pp.1895 - 1900.

[8] HUANG Ming-jun, ZHOU Tie-ying, WU Qing-hua. (2000). Effect of ultrasonic vibration on the frictional force. In: Chinese Journal of acoustics, Vol.25: pp.115 - 119.

[9] CHENG Guang-ming,Z ENG Ping,QIU Xiao-yang etc. (1998). Study on ultrasonic vibration antifriction phenomenon. In: Piezoelectrics \& Acoustooptics, Vol.20, pp.322 - 325.

[10] UEHA, SADAYUKI; HASHIMOTO, YOSHIKI; KOIKE etc. (2000). Non-contact transportation using near-field acoustic levitation, In: Ultrasonics, Vol. 38, pp.26 - 32.

[11] KOSHIZUKA, N., ISHIKAWA, K., NASU, H. etc, (2003). Progress of superconducting bearing technologies for flywheel energy storage systems, In: Physica 386: pp.444 - 450.

[12] MITAL, D., ZAJAC, J., HATALA, M. etc, (2014). Identification of Internal Residual Stress of Steel after Milling by Ultrasound, In: Manufacturing Technology Journal, Vol. 14, pp.573 - 578.

[13] VAJDOVÁ, A., MICIETOVA, A., NESLUSAN, M. etc, (2014). Analysis of Surface Integrity of Parts after Nonconventional Methods of Machining, In: Manufacturing Technology Journal, Vol. 14, pp.470 - 474.

[14] ADAMSTOLARSKI, T., KHONSARI, M.M. (2011). Running Characteristics of Aerodynamic Bearing with SelfLifting Capability at Low Rotational Speed. In: Advances in Tribology, pp.973-740. 